\title{
ATRIBUTOS QUÍMICOS E FÍSICOS DE LATOSSOLOS E SUA RELAÇÃO COM OS RENDIMENTOS DE MILHO E FEIJÃO IRRIGADOS ${ }^{(1)}$
}

\author{
Telmo Jorge Carneiro Amado ${ }^{(2)}$, Luciano Zucuni Pes ${ }^{(3)}$, Claudio Luiz \\ Lemainski $^{(4)}$ \& Ricardo Bergamo Schenato ${ }^{(5)}$
}

\begin{abstract}
RESUMO
Em sistemas de produção agrícola que utilizam a irrigação, uma das principais causas da variabilidade dos rendimentos, a disponibilidade de água para as culturas, é controlada. Nesse caso, outros fatores limitantes ao rendimento, relacionados a atributos de solo, passam a ter sua importância aumentada. Com o objetivo de investigar a variabilidade espacial dos principais atributos químicos e do rendimento de culturas, além de determinar os atributos químicos e físico-hídricos do solo em diferentes zonas de rendimento, foram analisadas duas áreas comerciais irrigadas por pivô central, com 51,8 e 58,2 ha, localizadas, respectivamente, em Trindade do Sul (TS) e Palmeira das Missões (PM), no Rio Grande do Sul (RS). As amostragens para caracterização dos atributos químicos foram georreferenciadas seguindo uma malha regular de $100 \times 100 \mathrm{~m}$, na camada de $0-0,10 \mathrm{~m}$. Já para investigar a relação entre os atributos químicos e físico-hídricos do solo com os rendimentos obtidos, dada a extensão das áreas, três zonas com distinto potencial produtivo foram estabelecidas, utilizando os mapas de rendimento disponíveis (safras de feijão-preto de 2005/2006 e safrinha de $2006 \mathrm{em}$ TS, e de milho de 2002/ 2003 e 2003/2004 em PM), obtidos por colhedoras equipadas com sensores de rendimento. Nessas zonas, quinze pontos amostrais foram investigados em cada área nas camadas de $0-0,05,0,05-0,10$ e $0,10-0,20 \mathrm{~m}$. Os atributos químicos do solo foram submetidos à análise de estatística descritiva e geoestatística. Eles apresentaram dependência espacial classificada como forte e moderada, com modelo ajustado à semivariância predominantemente esférico. $\mathrm{O} P$ apresentou a maior variabilidade espacial e o pH a menor. Embora manejadas sob irrigação, ambas as áreas apresentaram variabilidade espacial de rendimento. Na zona de
\end{abstract}

\footnotetext{
(1) Parte da Dissertação de Mestrado do terceiro autor, apresentada ao Programa de Pós-Graduação em Engenharia Agrícola (PPGEA), Universidade Federal de Santa Maria - UFSM. Recebido para publicação em outubro de 2008 e aprovado em abril de 2009.

(2) Professor Associado do Departamento de Solos, Universidade Federal de Santa Maria - UFSM. CEP 97110-900 Santa Maria (RS). Bolsista do CNPq. E-mail: tamado@smail.ufsm.br

(3) Engenheiro-Agrônomo, Mestrando em Engenharia Agrícola, UFSM. Bolsista da CAPES. E-mail: luciano_pes@hotmail.com

(4) Engenheiro-Agrônomo, Msc. Engenharia Agrícola, UFSM. E-mail: lemainski@hotamail.com

(5) Engenheiro-Agrônomo, Mestrando em Ciência do Solo, UFSM. Bolsista do CNPq. E-mail: ri_bschenato@yahoo.com.br
} 
baixo rendimento de TS, foram constatadas acidez no solo, baixa saturação de bases e menor capacidade de água disponível, e na de PM foram observadas limitações físicas representadas por compactação por meio dos indicadores densidade, resistência à penetração e macroporosidade. A ocorrência de zonas com menor rendimento das culturas irrigadas nas duas áreas foi associada a limitações químicas e físicas do solo, especialmente em subsuperfície.

Termos de indexação: agricultura de precisão; manejo do solo; fertilidade do solo; pivô central.

\title{
SUMMARY: CHEMICAL AND PHYSICAL ATTRIBUTES OF OXISOLS AND THEIR RELATION WITH IRRIGATED CORN AND COMMON BEAN YIELDS
}

\begin{abstract}
Under irrigated agriculture one of the main causes of yield variability, which is the plantavailable water, is controlled. In this case, other yield limitations caused by soil attributes become more relevant. To investigate the spatial variability of soil attributes and crop yields, besides the relation between chemical and physical-hydric soil attributes and crop yields of two irrigated commercial plantations (51.8 and $58.2 \mathrm{ha}$ ) were studied in Trindade do Sul (TS) and Palmeira das Missões (PM) respectively, in the state of Rio Grande do Sul, Brazil. The soil was sampled from a regular grid of $100 \times 100 \mathrm{~m}$ in the 0-0.10 m layer for chemical analysis. To investigate the relation between chemical and physical-hydric soil attributes and yields, due to the large area of the plantations, three soil management zones were established based on yield maps available (common bean in 2005/06 and 2006, in TS, and corn in 2002/03 and $2003 / 04$, in PM) recorded by harvesters equipped with yield sensors. In these zones, 15 grid points were sampled in the layers 0-0.05, 0.05-0.10 and 0.10-0.20 m to analyze soil attributes. These underlying soil data, analyzed by descriptive statistics and geostatistics, classified the spatial dependence as strong and moderate, with predominance of the spherical model. Spatial variability was highest for $P$ and lowest for $\mathrm{pH}$. Although both plantations were irrigated there was spatial variability in the yields. In the low-yield zone in TS soil acidity, low base saturation and lower available soil water capacity was diagnosed, while in PM the yield constraints were associated to soil compaction, expressed in the bulk density, soil resistance and macroporosity. The low yield zones of irrigated crops, in both croplands, were linked mainly to chemical and physical limitations in the subsurface.
\end{abstract}

Index terms: precision agriculture; soil management; soil fertility; central pivot.

\section{INTRODUÇÃO}

Um dos princípios da agricultura de precisão (AP) é a aplicação de insumos em taxa variada, de acordo com a variabilidade espacial e temporal dos atributos do solo e das culturas (Corá et al., 2004). Trata-se de um gerenciamento agrícola que parte do registro georreferenciado de informações de solo e de culturas, completando-se com intervenções de manejo localizado (Roza, 2000; Amado \& Santi, 2007). Nesse contexto, o conhecimento da variabilidade dos atributos de solo e de cultura apresenta-se como uma ferramenta útil para investigar a variabilidade de rendimento observada e aprimorar o manejo em áreas agrícolas (Salviano et al., 1998; Silva et al., 2003).

A coleta de amostras de solo georreferenciadas permite espacializar os atributos químicos, com o auxílio das ferramentas de geoestatística, sendo frequentemente utilizada, visando identificar zonas com restrições químicas que possam estar limitando o rendimento. Já a caracterização e a espacialização dos atributos físicos do solo em áreas comerciais têm sido pouco empregadas, devido às dificuldades inerentes ao processo de coleta e análise de grande quantidade de amostras. Também pode contribuir para o entendimento da variabilidade do rendimento (Silva et al., 2003), uma vez que restrições ao crescimento radicular e decréscimos na quantidade de água disponível às plantas influenciam o rendimento das culturas e a eficiência de fertilizantes (Delin \& Berglund, 2005). Especificamente, a espacialização da compactação em áreas comerciais é importante, pois ela ocorre de forma descontínua (Silva et al., 2004), adaptando-se ao manejo localizado.

Com a compactação do solo, ocorrem alterações nos atributos físicos, com destaque às reduções do volume 
de macroporos e aeração, acompanhados do incremento na resistência à penetração de raízes (Taylor et al., 1966; Letey, 1985; Tormena et al., 2002; Secco et al., 2004). Essas alterações influenciam a infiltração de água, que está relacionada diretamente com a macroporosidade do solo e resistência à penetração das raízes (Hillel, 1982; Nicoloso et al., 2008). Em semeadura direta (SD) no sul do Brasil, notadamente nas áreas com pouco uso de rotação de culturas e culturas de cobertura, têm sido observada a compactação do solo, devido ao histórico de pressões associadas ao trânsito de máquinas agrícolas (Silva et al., 2004; Michelon et al., 2007; Nicoloso et al., 2008), que podem contribuir para a variabilidade espacial do rendimento das culturas de grãos (Amado et al., 2007). Em Latossolos argilosos do Planalto do Rio Grande do Sul (RS), Santi (2007), investigando atributos de solo em zonas de baixo rendimento de áreas comerciais, verificou que a menor infiltração de água foi a principal explicação para a limitação do rendimento observada.

A irregularidade da distribuição da precipitação pluviométrica e, consequentemente, da disponibilidade de água em períodos críticos tem sido reconhecida como um dos principais fatores responsáveis pela variabilidade temporal dos rendimentos de milho (Lamb et al., 1997; Bakhsh et al., 2001; Miao et al., 2006) e do feijão-preto (Kluthcouski et al., 2000). A irrigação pode diminuir esta variabilidade, porém a eficiência desta prática em atender plenamente a demanda das plantas está relacionada, entre outros fatores, com a taxa de infiltração, a capacidade de armazenamento no solo e a disponibilidade de água às plantas, sendo, portanto, influenciada pelo estado de compactação. Beutler et al. (2007) relataram a existência de interação entre a irrigação e a compactação do solo, de modo que a irrigação amenizou o decréscimo de rendimento da soja em solo compactado. No entanto, quando o estado de compactação foi severo, mesmo sob irrigação, observouse decréscimo no rendimento da cultura.

Em áreas irrigadas por pivô central, onde os cultivos são mais intensivos, a umidade frequentemente é maior, assim como o trânsito e a operação de máquinas agrícolas, do que em áreas de sequeiro, sendo possível que as alterações nos atributos físicos do solo ocorram com maior rapidez e intensidade (Michelon et al., 2007). Ainda nessas condições, a variabilidade espacial dos atributos químicos do solo também pode ser aumentada, pois, com a maior frequência dos cultivos e os elevados rendimentos alcançados, haverá maior exportação de nutrientes via colheita e, consequentemente, maior demanda por fertilização, ambas são causas da variabilidade antrópica. Este fato requer a realização, em áreas irrigadas, de um acompanhamento mais frequente $\mathrm{e}$ detalhado dos atributos químicos e físicos do solo do que em áreas de sequeiro.

A variabilidade espacial dos atributos do solo em áreas irrigadas e seu impacto sobre o rendimento ainda é pouco conhecida no Brasil. O elevado investimento realizado nessas áreas, especialmente sob pivô central, justificam economicamente a investigação da variabilidade do solo e do rendimento das culturas. Este trabalho teve por objetivos caracterizar a variabilidade espacial dos atributos químicos do solo e relacionar atributos químicos e físico-hídricos do solo com os rendimentos de culturas irrigadas em dois Latossolos Vermelhos do RS.

\section{MATERIAL E MÉTODOS}

O estudo foi conduzido em duas áreas comerciais irrigadas por pivô central nos municípios de Trindade do Sul (TS) e Palmeira das Missões (PM), do RS. Em TS, a área perfazia 51,8 ha, representando $50 \%$ da área irrigada pelo pivô, situada entre as coordenadas UTM $324.538(\mathrm{Em})$ a $325.038(\mathrm{Em})$ e $6.950 .780(\mathrm{Nm})$ a $6.950 .780(\mathrm{Nm})$, fuso 22 sul, usando datum WGS84, com uma altitude média de $614 \mathrm{~m}$. O solo é classificado como Latossolo Vermelho distrófico aluminoférrico (Embrapa, 2006). O sistema de manejo empregado há aproximadamente onze anos é o da SD. O clima da região, segundo a classificação de Köppen, é do tipo $\mathrm{Cfa}$ - subtropical. A temperatura média anual é de $18,7^{\circ} \mathrm{C}$, com máxima de $39^{\circ} \mathrm{C}$ e mínima de $-5{ }^{\circ} \mathrm{C}$. A precipitação pluviométrica alcança $1.618 \mathrm{~mm} \mathrm{ano}^{-1}$ (Moreno, 1961). Já em PM, a área perfazia 58,2 ha, representando também $50 \%$ da área do pivô, situada entre as coordenadas UTM 262.517.3 (Em) a 263.417.3 (Em) e 6.919.887 (Nm) a 6.919.987 (Nm), fuso 22 sul, usando datum WGS84, com uma altitude aproximada de $576 \mathrm{~m}$. O solo é classificado como Latossolo Vermelho distrófico típico (Embrapa, 2006). O sistema de manejo empregado há aproximadamente dez anos é o da SD. O clima da região, segundo a classificação de Köppen, também é do tipo $\mathrm{Cfa}$ - subtropical. A temperatura média anual é de $19,6^{\circ} \mathrm{C}$, com máxima de $39,7^{\circ} \mathrm{C}$ e mínima de $3{ }^{\circ} \mathrm{C}$. A precipitação pluviométrica alcança $1.625 \mathrm{~mm} \mathrm{ano}^{-1}$ segundo Moreno (1961). Ambas as áreas apresentam pedoformas convexa no topo, linear na parte da meia encosta, e côncava na parte baixa do terreno, comuns em áreas agrícolas do planalto do RS. A declividade média da área em TS é de $6 \%$, enquanto em PM é de 4,5\%. Durante o período experimental, em TS foram realizadas oito irrigações por cultivo, e em PM, 12. Detalhes do manejo das áreas investigadas encontram-se descritos em Lemainski (2007).

Este trabalho constou de dois estudos. O primeiro baseou-se na avaliação da variabilidade espacial de atributos químicos e do rendimento, visando à caracterização inicial das áreas investigadas. O segundo visou estabelecer relações entre atributos químicos e físicos do solo com o rendimento das culturas em zonas de rendimento pré-estabelecidas. 
No estudo da variabilidade espacial dos atributos químicos, a amostragem foi realizada na safra 2005/ 2006, seguindo uma malha quadricular de $100 \times 100 \mathrm{~m}$, gerada por meio do programa computacional CR-Campeiro 5 (Giotto et al., 2004), totalizando 52 e 57 pontos em TS e PM, respectivamente. Os pontos de coleta foram localizados por meio de GPS de navegação portátil Garmin ${ }^{\circledR}$. As amostragens foram realizadas manualmente, com trado calador, dentro de um raio de $15 \mathrm{~m}$ no entorno do ponto georreferenciado. A amostra foi composta por 10 subamostras, sendo coletadas quatro na linha de semeadura e seis na entrelinha, representando a camada de 0-0,10 m. Esta profundidade é a atualmente recomendada pela CQFSRS/SC. (2004) para a SD consolidada. Os atributos químicos avaliados foram: pH em água (relação 1:1), índice SMP, teores de $\mathrm{P}$ e de K extraídos por Mehlich-1 (relação 1:10) e Al, $\mathrm{Ca}$ e $\mathrm{Mg}$ trocáveis extraídos por $\mathrm{KCl} 1 \mathrm{~mol} \mathrm{~L}^{-1}$. As determinações foram realizadas seguindo métodos descritos por Tedesco et al. (1995) no Laboratório de Manejo e Conservação do Solo da UFSM. Também foi determinado o teor de argila das amostras pelo método do densímetro (Embrapa, 1997). A partir desses dados, foi calculada a soma de bases, a CTC efetiva, a CTC em pH 7,0 e a saturação por bases (V) e por $\mathrm{Al}(\mathrm{m})$. O conteúdo de $\mathrm{C}$ orgânico foi determinado pelo método de combustão úmida, descrito por Nelson \& Sommers (1986) e expresso em matéria orgânica do solo (MOS).

A variabilidade espacial do rendimento foi investigada visando à determinação de distintas zonas de rendimento das culturas. Para isso, foram utilizados dados obtidos com colhedoras equipadas com sensores, computador de bordo para armazenamento de dados e GPS para localização espacial. O não uso das ferramentas da geoestatística para esta investigação justifica-se pelo reduzido número de safras disponíveis (duas por área), fato que não assegura que a variabilidade temporal esteja contemplada. Assim, a variabilidade espacial do rendimento deve ser investigada com um conjunto de vários anos. O elevado número de dados coletados por unidade de área, de 300 a 500 pontos por ha, provavelmente assegura que os valores registrados encontram-se dentro do limite da dependência espacial da variável. Anteriormente, Amado et al. (2007), investigando a variabilidade espacial de rendimentos, relataram que a distância de coleta de pontos amostrais, proporcionada pelas colhedoras, foi de 3 a $5 \mathrm{~m}$. Este valor é semelhante ao alcance do rendimento de milho (4,5 m) reportado por Silva et al. (2003). Os dados de produtividade georreferenciados da cultura de milho (Zea mays L.), em PM, foram obtidos nas safras de 2002/2003 e 2003/2004, com uma colhedora Massey Ferguson, modelo MF 34, equipada com o Sistema Fieldstar ${ }^{\circledR}$. Já na área de TS, os dados de produtividade do feijão-preto (Phaseolus vulgaris L.) foram coletados na safra 2005/2006 e na safrinha 2006, por uma colhedora CASE, modelo 2388, equipada com
Sistema $\mathrm{AFS}^{\circledR}$. A primeira colhedora não possuía sensor de umidade. Para a correção desse fator, durante a colheita, realizou-se, periodicamente, amostragem dos grãos, conforme proposto por Amado et al. (2007). A segunda colhedora possuía sensor de umidade, dispensando o procedimento. Em todas as colheitas, houve padronização de entrada e saída da lavoura, cuidados com limpeza de sensor, manutenção da plataforma totalmente preenchida por linhas da cultura e controle de manobras e de velocidade de deslocamente da máquina dentro da lavoura, visando melhorar a qualidade de registro de dados.

Os dados de colheita foram submetidos a um processo de filtragem, utilizando-se uma planilha eletrônica do Microsoft Excel $2003^{\circledR}$, a fim de identificar e eliminar eventuais erros ("outliers"), como proposto por Menegatti (2002), através da exclusão do registro dos dados com coordenadas fora da área colhida (erro de posicionamento), produtividade nula ou ausente e produtividade excessivamente elevada ou baixa. Após isso, os dados de colheita sofreram um processo de redução de densidade. Para isso, as áreas mapeadas foram subdivididas em células com dimensões de $13 \mathrm{x}$ $13 \mathrm{~m}$, nas quais foram determinados os rendimentos médios de cada célula, utilizando-se o programa computacional CR-Campeiro 5. Em cada uma dessas células, os dados das duas safras foram normalizados, classificados quanto a sua variabilidade, conforme método proposto por Molin (2002). Esse autor estabeleceu as classes de baixo rendimento $<95 \%$, de médio rendimento $95-105 \%$ e de alto rendimento $>105 \%$ do rendimento médio obtido na respectiva safra, interpolados e sobrepostos, a fim de gerar um único mapa para cada uma das áreas (Figura 1). As zonas de rendimento estabelecidas foram apresentadas e discutidas com os agricultores responsáveis pelas áreas, visando à sua validação em campo (Figura 1). Este procedimento se fez necessário porque o número de rendimentos mapeados (dois por área) ainda é limitado para caracterizar as variabilidades espacial e temporal (Blackmore et al., 2003; Amado et al., 2007).

No segundo estudo, foram amostrados, aleatoriamente, dentro de cada zona de rendimento, cinco pontos georreferenciados e investigados quanto aos atributos químicos e físico-hídricos do solo, visando relacioná-los com o rendimento. A amostragem dos atributos químicos foi realizada na área adjacente às trincheiras de coleta dos atributos físicos e seguindose método descrito no primeiro estudo em relação à profundidade de amostragem, número de subamostras e análise laboratorial. Para a determinação da densidade, porosidade total, microporosidade e macroporosidade do solo, foram abertas pequenas trincheiras nas quais foram coletadas amostras com estrutura preservada em anéis metálicos, com $0,06 \mathrm{~m}$ diâmetro e $0,04 \mathrm{~m}$ de altura, em três camadas: $0-0,05$, $0,05-0,10$ e $0,10-0,20 \mathrm{~m}$. Essas camadas foram escolhidas por compreenderem o intervalo de 0,075 a $0,175 \mathrm{~m}$, que é a mais frequentemente compactado sob SD mecanizada (Silva et al., 2000). 

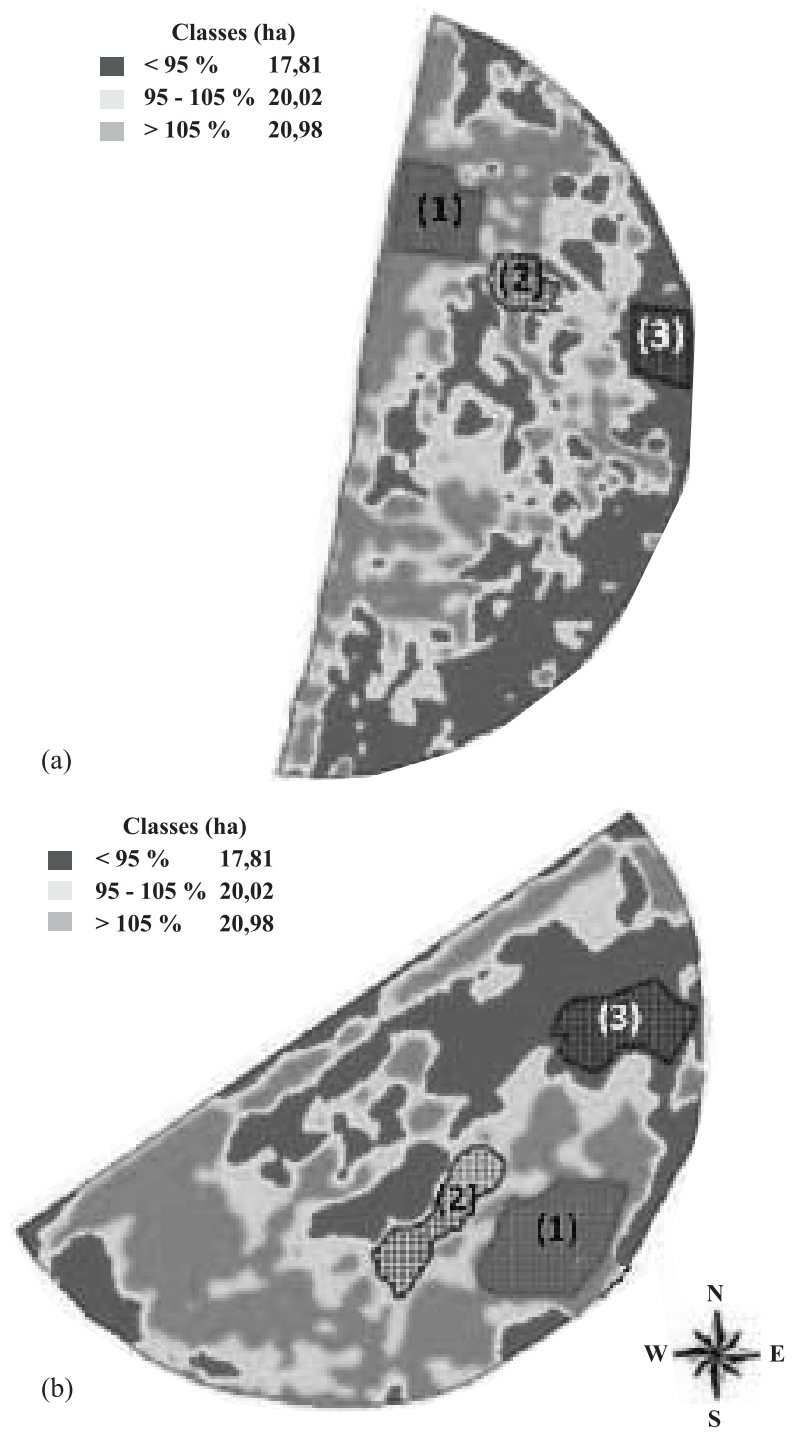

Figura 1. Espacialização das zonas de rendimento (1: zona de alto rendimento; 2: zona de médio rendimento; e 3: zona de baixo rendimento) de feijão-preto nas safras de 2005/2006 e $2006 \mathrm{em}$ Trindade do Sul (a) e de milho nas safras de 2002/ 2003 e 2003/2004 em Palmeira das Missões (b), nas quais foi feita a caracterização de atributos do solo.

A determinação da densidade de partículas (Dp) e do solo (Ds) seguiu o método descrito em Embrapa (1997), e a microporosidade foi determinada em mesa de tensão, conforme Oliveira (1968). A curva de retenção de água no solo foi determinada no Laboratório de Física do Solo da UFSM, através da saturação das amostras durante $24 \mathrm{~h}$ e subsequente submissão à tensão de $1 \mathrm{kPa}$ durante $72 \mathrm{~h}$. Após a drenagem da água retida no solo, as amostras foram pesadas e, posteriormente, colocadas de volta para serem submetidas à tensão de $6 \mathrm{kPa}$, onde também permaneceram durante mais $72 \mathrm{~h}$. Após tal procedimento foram pesadas e transferidas para a câmara de Richards, na qual foram submetidas à tensão $33 \mathrm{kPa}$ e, posteriormente, de $100 \mathrm{kPa}$ em placas porosas, na câmara de pressão. Uma vez cessada a drenagem, as amostras foram pesadas.

Não houve ressaturação das amostras após o equilíbrio em cada tensão, para submeter à tensão seguinte, apenas umedecimento do papel poroso. No final da última pesagem, foram levadas para estufa a $105^{\circ} \mathrm{C}$ por $48 \mathrm{~h}$, sendo pesadas novamente e calculada sua umidade volumétrica. A umidade a 500 e $1.500 \mathrm{kPa}$ foi obtida através do aparelho psicrômetro "Dewpoint Potentiometer - Decagon - modelo WP4" (WP4), no qual a umidade gravimétrica foi transformada em umidade volumétrica. Com os seis pontos determinados $(1,6,33,100,500$ e $1.500 \mathrm{kPa})$, ajustou-se a curva de retenção de água, da qual foram retiradas informações para a determinação dos valores de capacidade de água disponível $(\mathrm{CAD})$ e a quantidade total de água armazenada no solo (QTA).

A CAD foi calculada pela diferença de umidade volumétrica a 6 e $1.500 \mathrm{kPa}$ de tensão e a QTA pela diferença entre a umidade volumétrica da amostra do campo e a $1.500 \mathrm{kPa}$ de tensão. Portanto, neste trabalho, a tensão de $6 \mathrm{kPa}$ foi escolhida por ser recomendada para fazer a distinção entre os macroporos (poros $\geq 50 \mu \mathrm{m})$ e microporos (poros $<50 \mu \mathrm{m}$ ) (Embrapa, 1997). A CAD e QTA foram calculadas por camadas e, após, somadas, para obtenção da lâmina de água por zona em cada uma das áreas. A resistência do solo à penetração $(\mathrm{RP})$ foi determinada pelo índice de cone, por meio de penetrômetro digital (marca DLG, modelo PNT 2000), com armazenamento eletrônico dos dados. Foi realizada a avaliação nos cinco pontos escolhidos em cada zona de rendimento, e em cada ponto foram feitas cinco repetições, em duas épocas: antecedendo a semeadura e após a colheita das culturas de feijão em TS, e do milho em PM, utilizando-se o valor da média das determinações nas diferentes épocas. As profundidades avaliadas foram $0,05,0,10$ e $0,20 \mathrm{~m}$, visando à comparação com os demais atributos físicos investigados. Ainda, foram coletadas, concomitantemente, amostras para a determinação da umidade gravimétrica nas mesmas profundidades anteriores.

No primeiro estudo, efetuou-se uma análise estatística descritiva dos dados, utilizando o programa computacional Grapher (Golden Software version 3). A variabilidade dos atributos foi classificada, segundo proposto por Warrick \& Nielsen (1980), em baixa $(\mathrm{CV}<12 \%)$, média $(12 \leq \mathrm{CV} \geq 62 \%)$ e alta (CV > $62 \%$ ). A análise da variabilidade espacial dos atributos químicos foi feita através de semivariogramas experimentais (Isaaks \& Srvastava, 1989). O semivariograma é um gráfico que relaciona a semivariância de uma variável qualquer com uma distância (h) (Silva et al., 2003). Os parâmetros dos modelos ajustados aos semivariogramas foram: efeito pepita $\left(\mathrm{C}_{0}\right)$, que explica descontinuidade; alcance (a), que descreve a distância máxima nas quais as amostras são consideradas com dependência espacial; 
patamar $\left(\mathrm{C}=\mathrm{C}_{0}+\mathrm{C}_{1}\right)$, que representa o valor da semivariância quando a distância é igual ao valor do alcance (Guedes et al., 2008) e ainda o Índice de Dependência Espacial(IDE).

$\mathrm{O}$ ajuste de semivariogramas experimentais foi realizado pelo software GS+ (Gamma Design Software, 2000), testando três modelos teóricos (esférico, exponencial e gaussiano), considerados adequados aos dados em análise (Faraco et al., 2008). A escolha do modelo foi realizada observando-se o melhor coeficiente de correlação obtido pela técnica chamada de validação cruzada. Essa técnica consiste em retirar, individualmente, cada ponto medido da área estudada e o seu valor é estimado como se ele não existisse (Silva et al., 2003). Para analisar o grau de dependência espacial, por meio do cálculo do IDE, foi realizada uma modificação da classificação de Cambardella et al. (1994), subtraindo de uma unidade o resultado da divisão entre $\mathrm{C}_{0}$ e $_{0}+\mathrm{C}_{1}$ e multiplicando por 100, conforme apresentado por Silva et al. (2003). Nesse caso, foram considerados de dependência espacial forte os resultados $\geq 75 \%$, de dependência espacial moderada, quando entre 74 e $26 \%$, e de dependência fraca, quando $\leq 25 \%$.

Já no segundo estudo, foram determinados os rendimentos médios em torno dos cinco pontos escolhidos para relacioná-los com os atributos químicos e físico-hídricos do solo dentro de cada zona de rendimento. A comparação de médias entre as zonas de rendimento foi realizada por meio do Teste de Tukey a $5 \%$ utilizando o pacote estatístico SAS, versão 8.02 (SAS Institute Inc, Cary, NC). Os atributos químicos e físico-hídricos do solo foram interpretados com base nos teores e limites críticos reportados na literatura e apresentados no texto.

\section{RESULTADOS E DISCUSSÃO}

A estatística descritiva dos atributos químicos do solo avaliados em TS e PM, referente ao primeiro estudo, é apresentada no quadro 1. Os maiores valores de CV foram verificados no $\mathrm{P}$ em TS, que foi classificado como alto, de acordo com a classificação de Warrick \& Nielsen (1980), concordando com o observado por Carvalho et al. (2002) e Silva et al. (2003). Já em PM, o CV deste nutriente foi classificado como médio, concordando com o obtido anteriormente por Geypens et al. (1999) e Miao et al. (2006). Os valores de CV alto para o $\mathrm{P}$, como o encontrado na área de TS e baixo para $\mathrm{pH}$ e MOS, em ambas as áreas, estão de acordo com o reportado anteriormente por Schlindwein

Quadro 1. Parâmetros estatísticos dos atributos do solo avaliados nas áreas de Trindade do Sul e Palmeira das Missões, na camada $0-0,10 \mathrm{~m}$

\begin{tabular}{|c|c|c|c|c|c|c|c|c|}
\hline \multirow{2}{*}{ Local } & \multirow{2}{*}{ Variável } & \multicolumn{7}{|c|}{ Parâmetro estatístico } \\
\hline & & Mínimo & Máximo & Mediana & Média & Desvio-padrão & CV & Wilks-Shapiro $^{(1)}$ \\
\hline \multirow{12}{*}{$\mathrm{TS}^{(4)}$} & & & & & & & $\%$ & \\
\hline & Argila (g kg-1) & 641,7 & 812,8 & 739,4 & 740,1 & 45,8 & 6,2 & $0,94^{*}$ \\
\hline & $\mathrm{pH} \mathrm{H} \mathrm{H}_{2} \mathrm{O}(1: 1)$ & 4,8 & 5,9 & 5,5 & 5,4 & 0,3 & 5,2 & $0,95 \mathrm{~ns}$ \\
\hline & Fósforo (mg dm $\left.{ }^{-3}\right)$ & 1,0 & 45,5 & 13,1 & 14,4 & 9,00 & 62,2 & $0,92^{* *}$ \\
\hline & Potássio $\left(\mathrm{cmol}_{\mathrm{c}} \mathrm{dm}^{-3}\right)$ & 0,3 & 0,8 & 0,5 & 0,5 & 0,1 & 18,5 & $0,96 \mathrm{~ns}$ \\
\hline & Matéria Orgânica $\left(\mathrm{g} \mathrm{kg}^{-1}\right)$ & 32,7 & 41,0 & 36,6 & 36,4 & 2,1 & 5,8 & $0,96 \mathrm{~ns}$ \\
\hline & Alumínio $\left(\mathrm{cmol}_{\mathrm{c}} \mathrm{dm}^{-3}\right)$ & 0,3 & 1,7 & 0,9 & 0,9 & 0,4 & 43,3 & $0,96 \mathrm{~ns}$ \\
\hline & Magnésio $\left(\mathrm{cmol}_{\mathrm{c}} \mathrm{dm}^{-3}\right)$ & 1,0 & 3,1 & 2,0 & 2,0 & 0,5 & 25,7 & $0,96 \mathrm{~ns}$ \\
\hline & Cálcio $\left(\mathrm{cmol}_{\mathrm{c}} \mathrm{dm}^{-3}\right)$ & 2,6 & 6,9 & 4,6 & 4,6 & 0,9 & 20,6 & $0,98 \mathrm{~ns}$ \\
\hline & $\mathrm{CTC}_{\text {efetiva }}\left(\mathrm{cmol}_{\mathrm{c}} \mathrm{dm}^{-3}\right)$ & 5,7 & 10,3 & 8,0 & 8,0 & 1,1 & 13,2 & $0,98 \mathrm{~ns}$ \\
\hline & $\mathrm{m}(\%)^{(2)}$ & 3,0 & 17,9 & 11,5 & 11,0 & 4,4 & 39,8 & $0,94 * *$ \\
\hline & $\mathrm{V}(\%)^{(3)}$ & 44,0 & 75,6 & 60,3 & 59,2 & 7,4 & 12,4 & $0,97 \mathrm{~ns}$ \\
\hline \multirow{11}{*}{$\mathrm{PM}^{(5)}$} & Argila (g kg-1) & 500,5 & 840,7 & 610,7 & 618,3 & 77,3 & 12,5 & $0,95^{*}$ \\
\hline & $\mathrm{pH} \mathrm{H}_{2} \mathrm{O}(1: 1)$ & 5,7 & 6,7 & 6,3 & 6,3 & 0,2 & 4,0 & $0,96 \mathrm{~ns}$ \\
\hline & Fósforo (mg dm $\left.{ }^{-3}\right)$ & 11,3 & 23,7 & 15,0 & 15,9 & 3,6 & 22,5 & $0,90 * *$ \\
\hline & Potássio $\left(\mathrm{cmol}_{\mathrm{c}} \mathrm{dm}^{-3}\right)$ & 0,3 & 0,7 & 0,5 & 0,5 & 0,9 & 15,9 & $0,96 \mathrm{~ns}$ \\
\hline & Matéria Orgânica ( $\mathrm{g} \mathrm{kg}^{-1}$ ) & 22,0 & 34,0 & 30,0 & 30,1 & 2,5 & 8,4 & $0,94 \mathrm{~ns}$ \\
\hline & Alumínio $\left(\mathrm{cmol}_{\mathrm{c}} \mathrm{dm}^{-3}\right)$ & 0,0 & 0,0 & 0,0 & 0,0 & 0,0 & 0,0 & 0,00 \\
\hline & Magnésio $\left(\mathrm{cmol}_{\mathrm{c}} \mathrm{dm}^{-3}\right)$ & 1,1 & 2,1 & 1,5 & 1,5 & 0,2 & 13,2 & $0,99 \mathrm{~ns}$ \\
\hline & Cálcio $\left(\mathrm{cmol}_{\mathrm{c}} \mathrm{dm}^{-3}\right)$ & 4,7 & 7,6 & 5,9 & 6,0 & 0,7 & 11,3 & $0,97 \mathrm{~ns}$ \\
\hline & $\mathrm{CTC}_{\text {efetiva }}\left(\mathrm{cmol}_{\mathrm{c}} \mathrm{dm}^{-3}\right)$ & 6,4 & 9,9 & 7,9 & 8,0 & 0,8 & 9,9 & $0,97 \mathrm{~ns}$ \\
\hline & $\mathrm{m}(\%)^{(2)}$ & 0,0 & 0,0 & 0,0 & 0,0 & 0,0 & 0,0 & 0,00 \\
\hline & $\mathrm{V}(\%)^{(5)}$ & 67,0 & 89,3 & 82,5 & 81,4 & 5,0 & 6,3 & $0,95^{* *}$ \\
\hline
\end{tabular}

(1) Teste de Wilks-Shapiro para distribuição normal, significativo em níveis de ** $\mathrm{p} \leq 0,01 \mathrm{e} * \mathrm{p} \leq 0,05$, ns: não significativo, respectivamente. Significativo indica que a hipótese para distribuição normal é rejeitada. (2) m: saturação por alumínio no complexo de troca catiônica. ${ }^{(3)} \mathrm{V}$ : saturação por bases do complexo de troca cationnica. ${ }^{(4)}$ TS: Trindade do Sul. ${ }^{(5)}$ PM: Palmeira das Missões. 
\& Anghinoni (2000) e Corá et al. (2004). Os teores médios de $\mathrm{P}$ foram semelhantes entre as áreas (14,4 $\mathrm{mg} \mathrm{dm}^{-3}$ em TS e $15,9 \mathrm{mg} \mathrm{dm}^{-3}$ em PM). Já a amplitude deste atributo entre as áreas foi distinta. Enquanto em TS o CV do P foi de $62,2 \%$, com amplitude de 1,0 a $45,5 \mathrm{mg} \mathrm{dm}^{-3}$, em PM o CV foi de $22,5 \%$, com amplitude de 11,3 a $23,7 \mathrm{mg} \mathrm{dm}^{-3}$. Portanto, em TS, constatou-se maior variabilidade do $\mathrm{P}$ do que em PM. Sendo assim, a utilização do teor médio de $\mathrm{P}$ como critério de definição da dose de adubação fosfatada pode conduzir a erros, especialmente em TS. A ineficiência da utilização da taxa fixa de fertilização com base no teor médio do nutriente em áreas com elevada variabilidade espacial foi reportada anteriormente por Bongiovanni \& Lowenberg-Deboer (2004) e Corá et al. (2004).

Todos os atributos químicos do solo investigados apresentaram estrutura espacial, com dependência classificada como forte e moderada (Quadro 2), concordando com Silva et al. (2003) e Corá et al. (2004). A maioria dos modelos de ajuste dos semivariogramas foi o esférico. Este modelo tem sido o mais frequentemente adaptado para descrever semivariogramas de atributos de solo e de planta, conforme proposto por Salviano et al. (1998), Cambardella \& Karlen (1999), Geypens et al. (1999), Silva et al. (2003) e Miao et al.
(2006). Segundo Cambardella et al. (1994), os atributos que apresentam forte dependência espacial são mais influenciados por propriedades intrínsecas do solo, notadamente a textura e a mineralogia, enquanto os que apresentam fraca dependência são mais influenciados por fatores externos, como aplicações de fertilizantes e sistemas de preparo e cultura, ou seja, estão relacionados com o manejo do solo. Ambos os Latossolos Vermelhos investigados possuem elevado teor médio de argila (618,3 $\mathrm{g} \mathrm{kg}^{-1} \mathrm{em}$ PM e 740,1 $\mathrm{g} \mathrm{kg}^{-1}$ em TS) (Quadro 1) e mineralogia com óxidos de Fe e $\mathrm{Al}$, fato que explica a existência de atributos químicos com forte e moderada dependência espacial (Berg \& Klamt, 1997).

A variação no alcance dos semivariogramas ajustados dos atributos de solo teve amplitude de 102 a $510 \mathrm{~m}$ em TS e 220 a $561 \mathrm{~m}$ para PM (Quadro 2). Entre os atributos químicos, o $\mathrm{pH}$ apresentou elevado alcance, com $385 \mathrm{~m}$ em PM e $408 \mathrm{~m}$ em TS, valores estes próximos dos $357 \mathrm{~m}$ encontrados anteriormente por Miao et al. (2006). O P apresentou os menores alcances, com valores de $102 \mathrm{~m}$ em TS e $255 \mathrm{~m}$ em $\mathrm{PM}$, porém ambos superiores à faixa de 53 a $87 \mathrm{~m}$ encontrados por Cambardela \& Karlen (1999), Silva et al. (2003) e Miao et al. (2006). Com base nesses resultados, infere-se que quando o $\mathrm{P}$ for o nutriente

Quadro 2. Parâmetros geoestatísticos dos atributos de solo, avaliados na camada 0-0,10 m, em Trindade do Sul (TS) e Palmeira das Missões (PM)

\begin{tabular}{|c|c|c|c|c|c|c|c|}
\hline \multirow{2}{*}{ Local } & \multirow{2}{*}{ Variável } & \multirow{2}{*}{ Efeito pepita } & \multirow{2}{*}{ Patamar } & \multirow{2}{*}{ Alcance } & \multirow{2}{*}{ Modelo } & \multicolumn{2}{|c|}{ Dependência espacial } \\
\hline & & & & & & IDE & Classe \\
\hline \multirow{12}{*}{$\mathrm{TS}^{(1)}$} & & & & $\mathrm{m}$ & & $\%$ & \\
\hline & Argila (g kg-1) & 2,43 & 21,01 & 510 & Esférico & 88 & Forte \\
\hline & $\mathrm{pH} \mathrm{H}_{2} \mathrm{O}(1: 1)$ & 0,01 & 0,08 & 408 & Esférico & 88 & Forte \\
\hline & $\mathrm{P}\left(\mathrm{mg} \mathrm{dm}^{-3}\right)$ & 43,90 & 80,58 & 102 & Exponencial & 46 & Moderada \\
\hline & $\mathrm{K}\left(\mathrm{cmol}_{\mathrm{c}} \mathrm{dm}^{-3}\right)$ & 308,35 & 1567,24 & 408 & Esférico & 80 & Forte \\
\hline & $\mathrm{MO}\left(\mathrm{g} \mathrm{kg}^{-1}\right)$ & 0,01 & 0,04 & 156 & Esférico & 75 & Forte \\
\hline & $\mathrm{Al}\left(\mathrm{cmol}_{\mathrm{c}} \mathrm{dm}^{-3}\right)$ & 0,06 & 0,19 & 153 & Esférico & 68 & Moderada \\
\hline & $\mathrm{Mg}\left(\mathrm{cmol}_{\mathrm{c}} \mathrm{dm}^{-3}\right)$ & 0,01 & 0,04 & 220 & Esférico & 75 & Forte \\
\hline & $\mathrm{Ca}\left(\mathrm{cmol}_{\mathrm{c}} \mathrm{dm}^{-3}\right)$ & 0,18 & 0,89 & 459 & Exponencial & 80 & Forte \\
\hline & $\mathrm{CTC}_{\text {efetiva }}\left(\mathrm{cmol}_{\mathrm{c}} \mathrm{dm}^{-3}\right)$ & 0,22 & 0,59 & 204 & Esférico & 63 & Moderada \\
\hline & $\mathrm{m}(\%)$ & 13,86 & 54,28 & 480 & Esférico & 74 & Moderada \\
\hline & $\mathrm{V}(\%)$ & 5,14 & 19,10 & 204 & Esférico & 73 & Moderada \\
\hline \multirow{11}{*}{$\mathrm{PM}^{(2)}$} & Argila $\left(\mathrm{g} \mathrm{kg}^{-1}\right)$ & 7,06 & 59,77 & 561 & Esférico & 88 & Forte \\
\hline & $\mathrm{pH} \mathrm{H} \mathrm{H}_{2} \mathrm{O}(1: 1)$ & 0,02 & 0,06 & 385 & Esférico & 67 & Moderada \\
\hline & $\mathrm{P}\left(\mathrm{mg} \mathrm{dm}^{-3}\right)$ & 3,56 & 12,71 & 255 & Esférico & 72 & Moderada \\
\hline & $\mathrm{K}\left(\mathrm{cmol}_{\mathrm{c}} \mathrm{dm}^{-3}\right)$ & 183,34 & 930,04 & 416 & Esférico & 80 & Forte \\
\hline & $\mathrm{MO}\left(\mathrm{g} \mathrm{kg}^{-1}\right)$ & 0,01 & 0,06 & 459 & Esférico & 83 & Forte \\
\hline & $\mathrm{Al}\left(\mathrm{cmol}_{\mathrm{c}} \mathrm{dm}^{-3}\right)$ & 0,00 & 0,00 & 0 & - & 0 & \\
\hline & $\mathrm{Mg}\left(\mathrm{cmol}_{\mathrm{c}} \mathrm{dm}^{-3}\right)$ & 0,01 & 0,04 & 220 & Esférico & 75 & Forte \\
\hline & $\mathrm{Ca}\left(\mathrm{cmol}_{\mathrm{c}} \mathrm{dm}^{-3}\right)$ & 0,08 & 0,46 & 488 & Esférico & 83 & Forte \\
\hline & $\mathrm{CTC}_{\text {efetiva }}\left(\mathrm{cmol}_{\mathrm{c}} \mathrm{dm}^{-3}\right)$ & 0,14 & 0,63 & 510 & Exponencial & 78 & Forte \\
\hline & m (\%) & 0,00 & 0,00 & 0 & & 0 & - \\
\hline & $\mathrm{V}(\%)$ & 5,83 & 25,17 & 510 & Exponencial & 77 & Forte \\
\hline
\end{tabular}

${ }^{(1)}$ TS: Trindade do Sul. ${ }^{(2)}$ PM: Palmeira das Missões. Efeito Pepita $=\mathrm{C}_{0}$; Patamar $=\mathrm{C}_{0}+\mathrm{C}_{1}$; Alcance: distância após a qual os valores das propriedades não são espacialmente correlacionados; modelos ajustados aos semivariogramas experimentais: esférico, exponencial e gaussiano; Índice de Dependência Espacial - IDE (forte $\geq 75 \%$; moderada 74 a $26 \%$; fraca $\leq 25 \%$ ), segundo classificação modificada de Cambardella et al. (1994), apresentada por Silva et al. (2003). 
prioritário no programa de fertilização, a malha de amostragem deve ser densa, a fim de representar eficientemente a variabilidade espacial observada. $\mathrm{O}$ índice de dependência espacial variou de $46 \%$ para o $\mathrm{P}$ a $88 \%$ para a argila e $\mathrm{pH}$ em TS, e foi de $67 \%$ para o pH a $88 \%$ para a argila em PM.

Confrontando os teores médios de $\mathrm{Al}$, nota-se que no solo de $\mathrm{PM}$ não havia $\mathrm{Al}$ trocável na camada de 0 0,10 m, enquanto no de TS houve teores médios de $0,9 \mathrm{cmol}_{\mathrm{c}} \mathrm{dm}^{-3}$ (Quadro 1). Nesta última área, a presença de $\mathrm{Al}$ reflete o processo de reacidificação do solo, fazendo-se necessária a utilização do corretivo. As características mineralógicas do Latossolo aluminoférrico (TS) podem contribuir para um processo mais intenso de reacidificação em relação ao Latossolo distrófico (PM).

No quadro 3 são apresentadas as frequências dos valores de $\mathrm{pH}$ em água, saturação por bases (V) e teores de $\mathrm{P}$ e K, classificadas em classes conforme a CQFSRS/SC (2004). Em TS, 55,8\% dos pontos amostrais apresentaram pH classificado nas classes "baixo" e "muito baixo" e aproximadamente $80 \%$ tinham saturação por bases enquadrada nestas mesmas classes. Por outro lado, em PM, todos os pontos amostrais encontravam-se com $\mathrm{pH}$ e saturação por bases nas classes "médio" e "alto". Nesse sentido, os resultados confirmam que em TS a calagem é uma prática necessária para aumentar o potencial produtivo do solo. Com relação ao $\mathrm{K}$, os resultados confirmam que, em ambos os Latossolos Vermelhos, a disponibilidade do nutriente é elevada, com 82,8\% dos pontos amostrais de TS apresentando teor "muito alto" e, em PM, 61,1\%. Os teores de P em ambas as áreas apresentaram mais de $60 \%$ dos pontos amostrais na classe "muito alto".

Observa-se que as áreas investigadas têm comportamento distinto em relação a seus indicadores químicos de fertilidade nas zonas de rendimento estabelecidas (Quadro 4). Comparando-se os atributos químicos em TS, observa-se que, na zona de alto rendimento, houve incremento de $138 \%$ no teor de $\mathrm{P}$, $20 \%$ no de K, $55 \%$ no de $\mathrm{Ca}, 56 \%$ no de $\mathrm{Mg}$ e $20 \%$ na saturação por bases e decréscimos de $55 \%$ no teor de $\mathrm{Al}$ e 64 \% na saturação por $\mathrm{Al}$, em relação à zona de baixo rendimento (Quadro 4). Em PM, os atributos químicos do solo apresentaram-se acima dos teores críticos em todas as zonas de rendimento investigadas, enquanto em TS a saturação por bases e o $\mathrm{pH}$ foram, predominantemente, abaixo do teor crítico. A MOS na zona de baixo rendimento de PM foi $23 \%$ inferior

Quadro 3. Interpretação de valores de pH em água, saturação por bases (V), teores de potássio conforme as classes de CTC do solo em pH 7,0 e teores de fósforo no solo, extraído pelo método Mehlich-1, conforme o teor de argila (CQFSRS/SC, 2004) nas áreas de Trindade do Sul (TS) e Palmeira das Missões (PM)

\begin{tabular}{|c|c|c|c|c|}
\hline \multirow{3}{*}{ Atributo químico } & \multirow{3}{*}{ Classe do atributo } & \multirow{3}{*}{ Interpretação } & \multicolumn{2}{|c|}{ Local } \\
\hline & & & TS ${ }^{(1)}$ & $\mathbf{P M}^{(2)}$ \\
\hline & & & \multicolumn{2}{|c|}{ Frequência relativa } \\
\hline $\mathrm{pH} \mathrm{H} \mathrm{H}_{2} \mathrm{O}$ & $\begin{aligned} & \leq 5,0 \\
& 5,1-5,4 \\
& 5,5-6,0 \\
&> 6,0\end{aligned}$ & $\begin{array}{l}\text { Muito baixo } \\
\text { Baixo } \\
\text { Médio } \\
\text { Alto }\end{array}$ & $\begin{array}{r}12,5 \\
43,3 \\
44,2 \\
0,0\end{array}$ & $\begin{array}{r}0,0 \\
0,0 \\
14,4 \\
85,6\end{array}$ \\
\hline $\mathrm{V}(\%)$ & $\begin{aligned}< & 45 \\
& 45-64 \\
& 65-80 \\
> & 80\end{aligned}$ & $\begin{array}{l}\text { Muito baixo } \\
\text { Baixo } \\
\text { Médio } \\
\text { Alto }\end{array}$ & $\begin{array}{r}1,2 \\
78,6 \\
20,2 \\
0,0\end{array}$ & $\begin{array}{r}0,0 \\
0,0 \\
31,1 \\
68,9\end{array}$ \\
\hline \multirow{5}{*}{$\begin{array}{c}\text { Potássio } \\
\left(\mathrm{cmol}_{\mathrm{c}} \mathrm{dm}^{-3}\right)\end{array}$} & $\leq 0,08\left(\mathrm{CTC}_{\mathrm{pH} 7}{ }^{(3)}>15\right)$ e $\leq 0,05\left(\mathrm{CTC}_{\mathrm{pH} 7} 5-15\right)$ & Muito baixo & 0,0 & 0,0 \\
\hline & $0,08-0,15\left(\mathrm{CTC}_{\mathrm{pH} 7}>15\right) 0,05-0,10\left(\mathrm{CTC}_{\mathrm{pH} 7} 5-15\right)$ & Baixo & 0,0 & 0,0 \\
\hline & $0,15-0,23\left(\mathrm{CTC}_{\mathrm{pH} 7}>15\right)$ e $0,10-0,15\left(\mathrm{CTC}_{\mathrm{pH} 7} 5-15\right)$ & Médio & 0,0 & 0,0 \\
\hline & $0,23-0,46\left(\mathrm{CTC}_{\mathrm{pH}}>15\right)$ e $0,15-0,31\left(\mathrm{CTC}_{\mathrm{pH} 7} 5-15\right)$ & Alto & 17,2 & 38,9 \\
\hline & $>0,46\left(\mathrm{CTC}_{\mathrm{pH} 7}>15\right)$ e $>0,31\left(\mathrm{CTC}_{\mathrm{pH} 7} 5-15\right)$ & Muito alto & 82,8 & 61,1 \\
\hline \multirow{5}{*}{$\begin{array}{c}\text { Fósforo } \\
\left(\mathrm{mg} \mathrm{dm} \mathrm{dm}^{-3}\right)\end{array}$} & $\leq 2,0\left(\right.$ argila $\left.>600^{(4)}\right)$ e $\leq 3,0($ argila $410-600)$ & Muito baixo & 0,2 & 0,0 \\
\hline & $2,1-4,0$ (argila $>600)$ e $3,1-6,0$ (argila $410-600)$ & Baixo & 1,8 & 0,0 \\
\hline & $4,1-6,0($ argila $>600)$ e $6,1-9,0$ (argila 410-600) & Médio & 5,1 & 0,0 \\
\hline & $6,1-12,0($ argila $>600)$ e $9,1-18,0$ (argila $410-600)$ & Alto & 31,4 & 36,8 \\
\hline & $>12($ argila $>600)$ e $0>18($ argila $410-600)$ & Muito alto & 61,5 & 63,2 \\
\hline
\end{tabular}

(1) TS: Trindade do Sul. ${ }^{(2)}$ PM: Palmeira das Missões. ${ }^{(3)}$ Valores de $\mathrm{CTC}_{\mathrm{pH}} 7$ expressos em $\mathrm{cmol}_{\mathrm{c}} \mathrm{dm}^{-3}$. ${ }^{(4)}$ Valores de argila expressos em $\mathrm{g} \mathrm{kg}^{-1}$. 
Quadro 4. Média dos teores de atributos do solo e produtividade, avaliados nas zonas de rendimento de Trindade do Sul (TS) e Palmeira das Missões (PM), na camada de 0-0,10 m

\begin{tabular}{|c|c|c|c|c|c|c|}
\hline \multirow{3}{*}{ Variável } & \multicolumn{5}{|c|}{ Área experimental / Zona de rendimento ${ }^{(1)}$} & \\
\hline & \multicolumn{3}{|c|}{ Trindade do Sul } & \multicolumn{3}{|c|}{ Palmeira das Missões } \\
\hline & ZB & ZM & $\mathbf{Z A}$ & ZB & $\mathbf{Z M}$ & $\mathbf{Z A}$ \\
\hline Argila (g kg-1) & $700,2 \mathrm{a}^{(2)}$ & $710,0 \mathrm{a}$ & $702,7 \mathrm{a}$ & $792,2 \mathrm{a}$ & $617,1 \mathrm{~b}$ & $623,3 \mathrm{~b}$ \\
\hline $\mathrm{pH} \mathrm{H} \mathrm{H}_{2} \mathrm{O}(1: 1)$ & $5,2 \mathrm{c}$ & $5,6 \mathrm{~b}$ & $5,7 \mathrm{a}$ & $6,4 \mathrm{~b}$ & $6,6 \mathrm{a}$ & $6,6 \mathrm{a}$ \\
\hline Fósforo (mg dm-3) & $7,7 \mathrm{~b}$ & 20,6 a & $18,3 \mathrm{a}$ & $17,0 \mathrm{a}$ & $13,3 \mathrm{a}$ & $14,9 \mathrm{a}$ \\
\hline Potássio $\left(\mathrm{cmol}_{\mathrm{c}} \mathrm{dm}^{-3}\right)$ & $0,5 \mathrm{~b}$ & $0,6 \mathrm{a}$ & $0,6 \mathrm{a}$ & $0,4 \mathrm{~b}$ & $0,5 \mathrm{a}$ & $0,4 \mathrm{~b}$ \\
\hline Matéria Orgânica (g kg-1) & $38,1 \mathrm{a}$ & $38,0 \mathrm{a}$ & $37,9 \mathrm{a}$ & $24,9 \mathrm{~b}$ & $32,1 \mathrm{a}$ & $32,2 \mathrm{a}$ \\
\hline Alumínio $\left(\mathrm{cmol}_{\mathrm{c}} \mathrm{dm}^{-3}\right)$ & $1,1 \mathrm{a}$ & $0,4 \mathrm{c}$ & $0,5 \mathrm{~b}$ & 0,0 & 0,0 & 0,0 \\
\hline Magnésio $\left(\mathrm{cmol}_{\mathrm{c}} \mathrm{dm}^{-3}\right)$ & $1,6 \mathrm{~b}$ & $2,2 \mathrm{a}$ & $2,5 \mathrm{a}$ & $1,9 \mathrm{a}$ & $1,7 \mathrm{~b}$ & $1,5 \mathrm{~b}$ \\
\hline Cálcio $\left(\mathrm{cmol}_{\mathrm{c}} \mathrm{dm}^{-3}\right)$ & $3,8 \mathrm{c}$ & $5,1 \mathrm{~b}$ & $5,9 \mathrm{a}$ & $7,1 \mathrm{a}$ & $5,9 \mathrm{~b}$ & $5,9 \mathrm{~b}$ \\
\hline $\mathrm{CTC}_{\text {efetiva }}\left(\mathrm{cmol}_{\mathrm{c}} \mathrm{dm}^{-3}\right)$ & $7,0 \mathrm{c}$ & $8,4 \mathrm{~b}$ & $9,5 \mathrm{a}$ & $9,3 \mathrm{a}$ & $8,0 \mathrm{~b}$ & $7,9 \mathrm{~b}$ \\
\hline $\mathrm{m}(\%)^{(3)}$ & $16,1 \mathrm{a}$ & $5,3 \mathrm{~b}$ & $5,8 \mathrm{~b}$ & 0,0 & 0,0 & 0,0 \\
\hline $\mathrm{V}(\%)^{(4)}$ & $59,2 \mathrm{~b}$ & $61,4 \mathrm{~b}$ & $71,2 \mathrm{a}$ & $85,3 \mathrm{a}$ & 86,5 a & $86,8 \mathrm{a}$ \\
\hline Produção de Grãos ${ }^{(5)}\left(\mathrm{Mg} \mathrm{ha}^{-1}\right)$ & $1,0 \mathrm{~b}(\mathrm{~F})$ & $1,2 \mathrm{~b}(\mathrm{~F})$ & $1,5 \mathrm{a}(\mathrm{F})$ & $6,9 \mathrm{c}(\mathrm{M})$ & $8,7 \mathrm{~b}(\mathrm{M})$ & $9,7 \mathrm{a}(\mathrm{M})$ \\
\hline
\end{tabular}

(1) Zonas de rendimento: ZB: zona de baixo rendimento, ZB: zona de médio rendimento e ZA: zona de alto rendimento. ${ }^{(2)}$ Médias seguidas da mesma letra, na linha, na mesma área experimental, não diferem entre si pelo teste de Tukey a 5 \%. ${ }^{(3)}$ m: saturação por alumínio no complexo de troca catiônica. ${ }^{(4)} \mathrm{V}$ : saturação por bases do complexo de troca catiônica. ${ }^{(5)}$ Médias de duas safras, TS - 2005/2006 (safra) e 2006/06 (safrinha) de feijão (F) e PM, safras de milho (M) 2002/2003 e 2003/2004.

em relação à de alto, resultado que concorda com Pontelli (2006), que verificou que a MOS foi o atributo que melhor se relacionou com o rendimento nesta mesma área. Conceição et al. (2005) relataram que a MOS foi o mais eficiente indicador em discriminar a qualidade do solo sob SD, investigando dois Argissolos. Quanto ao rendimento médio alcançado nas zonas, observou-se que, na zona de baixo rendimento de TS e $\mathrm{PM}$, houve redução de 33 e $29 \%$, respectivamente, em relação à zona de alto rendimento (Quadro 4).

Os atributos físicos nas diferentes zonas de rendimento, determinadas no segundo estudo, são apresentados no quadro 5. Suzuki et al. (2006) definiram valores de densidade crítica, através de equação ajustada da relação do teor de argila e a densidade do solo, e os solos com $640 \mathrm{~g} \mathrm{~kg}^{-1}$ de argila (textura muito argilosa) teriam valor de $1,32 \mathrm{Mg} \mathrm{m}^{-3}$. Este valor é ligeiramente superior ao reportado por Beutler et al. (2007), que encontraram um valor crítico de $1,29 \mathrm{Mg} \mathrm{m}^{-3}$ para áreas irrigadas de soja. Considerando-se este último valor como referência, por ter sido obtido em área irrigada, observa-se que em PM as zonas de baixo e médio rendimento apresentaram densidade do solo superior à crítica em todas as profundidades investigadas. Já a zona de alto rendimento somente apresentou densidade do solo superior à crítica na camada de 0,10-0,20 m. Em TS, a densidade foi inferior à crítica em todas as zonas e profundidades investigadas, com exceção da zona de média na profundidade $0,10-0,20 \mathrm{~m}$. A densidade do solo não se mostrou um indicador discriminatório das diferentes zonas de rendimento, em ambas as áreas, uma vez que não foi verificada diferença estatística deste atributo nas zonas, exceção da camada de $0-0,05 \mathrm{~m}$ em TS.

Cunha et al. (2002), Tormena et al. (2002) e Nicoloso et al. (2008) encontraram correlação entre $\mathrm{RP}$ e os valores de densidade e umidade do solo. Taylor et al. (1966) relataram que o limite crítico para resistência mecânica à penetração de raízes seria de 2,0 Mpa, com umidade do solo próxima da capacidade de campo. Araujo et al. (2004) e Lima et al. (2006) encontraram uma relação inversa entre a resistência à penetração e a umidade do solo. O aumento da resistência à penetração com a diminuição da umidade pode estar relacionado à maior coesão entre as partículas minerais do solo (Araujo et al., 2004). Recentemente, Beutler et al. (2007) concluíram a RP crítica para a soja irrigada foi de $1,64 \mathrm{Mpa}$. Com base neste último valor, observa-se que em TS todos os valores encontrados estavam abaixo do crítico, exceção da zona de médio rendimento na profundidade de $0,20 \mathrm{~m}$. Já em PM, na profundidade de $0,20 \mathrm{~m}$, todas as zonas de manejo apresentariam RP superior à crítica, com destaque a zona de baixo rendimento, que já apresentava valor acima do crítico na profundidade de $0,10 \mathrm{~m}$. A pequena diferença de umidade do solo, que foi próxima de $75 \%$ do limite superior de disponiblidade de água $(6 \mathrm{kPa})$, entre as zonas de rendimento (Quadro 5), provavelmente não interferiu na comparação das zonas de rendimento quanto à resistência à penetração. Considerando o valor crítico de macroporosidade de $0,10 \mathrm{~m}^{3} \mathrm{~m}^{-3}$, proposto por Taylor et al. (1966), observou-se que somente em PM, na zona de baixo rendimento, na profundidade de $0,10-0,20 \mathrm{~m}$, é que se verificou valor inferior a este. 
Quadro 5. Média da produção de grãos, densidade de partículas, densidade do solo, resistência à penetração, macroporosidade, microporosidade e porosidade total, avaliados nas zonas de rendimento em Trindade do Sul (TS) e Palmeira das Missões (PM)

\begin{tabular}{|c|c|c|c|c|c|c|c|}
\hline \multirow{3}{*}{ Variável } & \multirow{3}{*}{ Profundidade } & \multicolumn{6}{|c|}{ Área experimental / Zonas de rendimento } \\
\hline & & \multicolumn{3}{|c|}{ Trindade do Sul } & \multicolumn{3}{|c|}{ Palmeira das Missões } \\
\hline & & $\mathbf{Z B}^{(1)}$ & ZM & ZA & ZB & ZM & $\overline{Z A}$ \\
\hline $\begin{array}{l}\text { Produção de feijão (TS) e } \\
\text { milho (PM) }{ }^{(2)}\left(\mathrm{Mg} \mathrm{ha}^{-1}\right)\end{array}$ & $\begin{array}{c}m \\
-\end{array}$ & $1,0 \mathrm{~b}^{(3)}$ & $1,2 \mathrm{~b}$ & $1,5 \mathrm{a}$ & $6,9 \mathrm{c}$ & $8,7 \mathrm{~b}$ & $9,7 \mathrm{a}$ \\
\hline $\mathrm{Dp}\left(\mathrm{Mg} \mathrm{m}^{-3}\right)$ & $\begin{array}{l}0-0,05 \\
0,05-0,10 \\
0,10-0,20\end{array}$ & $\begin{array}{l}2,70 \\
2,72 \\
2,59\end{array}$ & $\begin{array}{l}2,65 \\
2,69 \\
2,70\end{array}$ & $\begin{array}{l}2,68 \\
2,69 \\
2,72\end{array}$ & $\begin{array}{l}2,76 \\
2,82 \\
2,80\end{array}$ & $\begin{array}{l}2,85 \\
2,80 \\
2,81\end{array}$ & $\begin{array}{l}2,77 \\
2,65 \\
2,69\end{array}$ \\
\hline Densidade $\left(\mathrm{Mg} \mathrm{m}^{-3}\right)$ & $\begin{array}{l}0-0,05 \\
0,05-0,10 \\
0,10-0,20\end{array}$ & $\begin{array}{l}1,15 \mathrm{a} \\
1,19 \mathrm{a} \\
1,27 \mathrm{a}\end{array}$ & $\begin{array}{l}0,91 \mathrm{~b} \\
1,18 \mathrm{a} \\
1,32 \mathrm{a}\end{array}$ & $\begin{array}{l}1,06 \mathrm{ab} \\
1,18 \mathrm{a} \\
1,21 \mathrm{a}\end{array}$ & $\begin{array}{l}1,35 \mathrm{a} \\
1,37 \mathrm{a} \\
1,42 \mathrm{a}\end{array}$ & $\begin{array}{l}1,31 \mathrm{a} \\
1,39 \mathrm{a} \\
1,36 \mathrm{a}\end{array}$ & $\begin{array}{l}1,22 \mathrm{a} \\
1,27 \mathrm{a} \\
1,32 \mathrm{a}\end{array}$ \\
\hline $\mathrm{RP}$ (Mpa) & $\begin{array}{l}0,05 \\
0,10 \\
0,20\end{array}$ & $\begin{array}{l}0,20 \mathrm{~b} \\
0,96 \mathrm{ab} \\
1,25 \mathrm{~b}\end{array}$ & $\begin{array}{l}0,38 \mathrm{a} \\
1,06 \mathrm{a} \\
1,68 \mathrm{a}\end{array}$ & $\begin{array}{l}0,16 \mathrm{~b} \\
0,88 \mathrm{~b} \\
1,27 \mathrm{~b}\end{array}$ & $\begin{array}{l}0,25 \mathrm{a} \\
1,72 \mathrm{a} \\
2,40 \mathrm{a}\end{array}$ & $\begin{array}{l}0,12 \mathrm{~b} \\
1,11 \mathrm{~b} \\
2,08 \mathrm{a}\end{array}$ & $\begin{array}{l}0,06 \mathrm{~b} \\
0,83 \mathrm{~b} \\
2,02 \mathrm{a}\end{array}$ \\
\hline Umidade (kg kg-1) & $\begin{array}{l}0,05 \\
0,10 \\
0,20\end{array}$ & $\begin{array}{l}0,36 \\
0,30 \\
0,33\end{array}$ & $\begin{array}{l}0,35 \\
0,33 \\
0,32\end{array}$ & $\begin{array}{l}0,35 \\
0,33 \\
0,31\end{array}$ & $\begin{array}{l}0,27 \\
0,32 \\
0,34\end{array}$ & $\begin{array}{l}0,26 \\
0,32 \\
0,37\end{array}$ & $\begin{array}{l}0,28 \\
0,34 \\
0,39\end{array}$ \\
\hline Macroporosidade $\left(\mathrm{m}^{3} \mathrm{~m}^{-3}\right)$ & $\begin{array}{l}0-0,05 \\
0,05-0,10 \\
0,10-0,20\end{array}$ & $\begin{array}{l}0,31 \mathrm{a} \\
0,25 \mathrm{a} \\
0,19 \mathrm{a}\end{array}$ & $\begin{array}{l}0,30 \mathrm{a} \\
0,22 \mathrm{a} \\
0,17 \mathrm{a}\end{array}$ & $\begin{array}{l}0,30 \mathrm{a} \\
0,22 \mathrm{a} \\
0,16 \mathrm{a}\end{array}$ & $\begin{array}{l}0,11 \mathrm{a} \\
0,10 \mathrm{a} \\
0,08 \mathrm{a}\end{array}$ & $\begin{array}{l}0,11 \mathrm{a} \\
0,10 \mathrm{a} \\
0,10 \mathrm{a}\end{array}$ & $\begin{array}{l}0,14 \mathrm{a} \\
0,13 \mathrm{a} \\
0,12 \mathrm{a}\end{array}$ \\
\hline Microporosidade $\left(\mathrm{m}^{3} \mathrm{~m}^{-3}\right)$ & $\begin{array}{l}0-0,05 \\
0,05-0,10 \\
0,10-0,20\end{array}$ & $\begin{array}{l}0,36 \mathrm{a} \\
0,39 \mathrm{a} \\
0,41 \mathrm{~b}\end{array}$ & $\begin{array}{l}0,36 \mathrm{a} \\
0,41 \mathrm{a} \\
0,44 \mathrm{ab}\end{array}$ & $\begin{array}{l}0,38 \mathrm{a} \\
0,38 \mathrm{a} \\
0,44 \mathrm{a}\end{array}$ & $\begin{array}{l}0,47 \mathrm{a} \\
0,46 \mathrm{a} \\
0,49 \mathrm{a}\end{array}$ & $\begin{array}{l}0,47 \mathrm{a} \\
0,46 \mathrm{a} \\
0,41 \mathrm{a}\end{array}$ & $\begin{array}{l}0,46 \mathrm{a} \\
0,44 \mathrm{a} \\
0,44 \mathrm{a}\end{array}$ \\
\hline Porosidade total $\left(\mathrm{m}^{3} \mathrm{~m}^{-3}\right)$ & $\begin{array}{l}0-0,05 \\
0,05-0,10 \\
0,10-0,20\end{array}$ & $\begin{array}{l}0,67 \mathrm{a} \\
0,64 \mathrm{a} \\
0,60 \mathrm{a}\end{array}$ & $\begin{array}{l}0,66 \mathrm{a} \\
0,63 \mathrm{a} \\
0,61 \mathrm{a}\end{array}$ & $\begin{array}{l}0,68 \mathrm{a} \\
0,60 \mathrm{a} \\
0,60 \mathrm{a}\end{array}$ & $\begin{array}{l}0,58 \mathrm{a} \\
0,56 \mathrm{a} \\
0,57 \mathrm{a}\end{array}$ & $\begin{array}{l}0,58 \mathrm{a} \\
0,56 \mathrm{a} \\
0,51 \mathrm{a}\end{array}$ & $\begin{array}{l}0,60 \mathrm{a} \\
0,57 \mathrm{a} \\
0,56 \mathrm{a}\end{array}$ \\
\hline
\end{tabular}

(1) Zonas de rendimento: ZB: zona de baixo rendimento, ZB: zona de médio rendimento e ZA: zona de alto rendimento. ${ }^{(2)}$ Médias de duas safras, TS - 2005/2006 (safra) e 2006/06 (safrinha) e, PM safras 2002/2003 e 2003/2004. TS - Trindade do Sul, RS; PM Palmeira das Missões. ${ }^{(3)}$ Médias seguidas da mesma letra, na linha, na mesma área experimental, não diferem entre si pelo teste de Tukey a $5 \%$.

Interpretando os resultados de atributos físicos nas duas áreas, pode-se inferir que, no geral, com o aumento da profundidade, houve um incremento na densidade e resistência à penetração, acompanhado de decréscimos na macroporosidade e porosidade total. A área de PM apresentou maior estado de compactação do que TS, especialmente na zona de baixo rendimento (Quadro 5). Michelon et al. (2007), avaliando as condições físicas de solos sob pivô central no RS, registraram que $66,5 \%$ das áreas investigadas apresentavam compactação do solo na camada de 0 $0,25 \mathrm{~m}$.

Na figura 2 são apresentados os valores de CAD e de QTA das zonas de rendimento para as duas áreas comerciais. A relação entre o rendimento de grãos e a CAD na camada superficial do solo foi reportada anteriormente por Timlin et al. (2001) e Delin \& Berglund (2005). A zona de baixo rendimento, em $\mathrm{TS}$, apresentou a CAD $38 \%$ inferior à zona de alto rendimento. Em PM verificou-se a mesma tendência, porém a redução observada foi de $16 \%$ e não houve diferença estatística entre as zonas de rendimento. Sendo assim, esses resultados suportam a menor redução no rendimento em PM do que TS, observada na zona de baixo rendimento em relação à de alto. Já a QTA não apresentou diferença entre as zonas. Portanto, a CAD foi um indicador mais sensível às alterações no potencial de rendimento do que a QTA no solo (Figura 2).

\section{CONCLUSÕES}

1. Os atributos químicos apresentaram dependência espacial classificada como forte e moderada, com modelo ajustado à semivariância predominantemente esférica. $\mathrm{O} \mathrm{P}$ apresentou a maior variabilidade espacial e o $\mathrm{pH}$ a menor. 

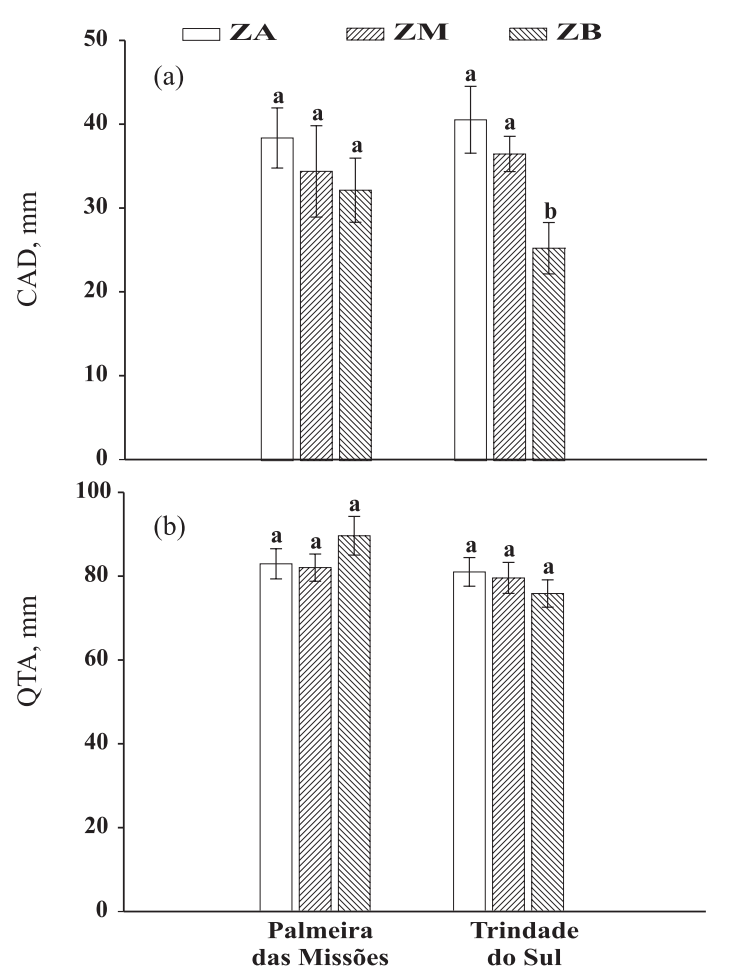

Figura 2. Histograma da capacidade de armazenamento de água (CAD) e da quantidade total de água disponível no solo (QTA) para as três zonas de rendimento na camada $0-0,2 \mathrm{~m}$, nas áreas experimentais de Trindade do Sul (TS) e de Palmeira das Missões (PM). As barras de erro correspondem ao desvio-padrão. Médias seguidas da mesma letra minúscula, na mesma área experimental, não diferem entre si pelo teste de Tukey a $5 \%$.

2. Mesmo manejadas sob irrigação, ambas as áreas apresentaram variabilidade espacial de rendimento, com distribuição de frequência uniforme entre as três classes de rendimento estabelecidas (baixo, médio e alto).

3. Em ambas as áreas, as principais limitações ao rendimento das culturas foram observadas em subsuperfície. Em Trindade do Sul, foram relacionadas aos atributos químicos, principalmente a acidez do solo e à baixa disponibilidade de bases, e em Palmeira das Missões, ao estado de compactação do solo.

4. Em Trindade do Sul, a zona de baixo rendimento apresentou menor quantidade total de água armazenada no solo e menor capacidade de água disponível do que as zonas de alto e médio rendimento. Nesse caso, a capacidade de água disponível foi um indicador mais sensível à alteração no rendimento do que a quantidade total de água armazenada no solo.

\section{AGRADECIMENTOS}

À família Sulzbach, pelo apoio e cessão da área em Palmeira das Missões para investigação, e ao sr.
Fernando Picolli e a AGROS, pela disponibilização da área em Trindade do Sul.

\section{LITERATURA CITADA}

AMADO, T.J.C.; PONTELLI, C.B.; SANTI, A.L.; VIANA, J.H.M. \& SULZBACH, L.A.S. Variabilidade espacial e temporal da produtividade de culturas sob sistema plantio direto. Pesq. Agropec. Bras., 42:1101-1110, 2007.

AMADO, T.J.C. \& SANTI, A.L. Agricultura de precisão aplicada ao aprimoramento do manejo do solo. In: FIORIN, J.E., ed. Manejo da fertilidade do solo no sistema plantio direto. Passo Fundo, Berthier, 2007. p.99-144.

ARAUJO, M.A.; TORMENA, C.A. \& SILVA, A.P. Propriedades físicas de um Latossolo Vermelho distrófico cultivado e sob mata nativa. R. Bras. Ci. Solo, 28:337-345, 2004.

BAKHSH, A.; JAYNES, D.B.; COLVIN, T.S. \& KANWAR, R.S. Spatio-temporal analysis of yield variability for cornsoybean field in Iowa. Trans. Am. Soc. Agric. Eng., 43:31$38,2001$.

BERG, M.V.D. \& KLAMT, E. Variabilidade espacial de características de solos na Região do Planalto Médio, RS: I. Análise da variância por amostragem aninhada. R. Bras. Ci. Solo, 21:393-399, 1997.

BEUTLER, A.N.; CENTURION, J.F.; CENTURION, M.A.P.C.; LEONEL, C.L.; SÃO JOÃO, A.C.G. \& FREDDI, O.S. Intervalo hídrico ótimo no monitoramento da compactação e da qualidade física de um Latossolo Vermelho cultivado com soja. R. Bras. Ci. Solo, 31:12231232, 2007.

BLACKMORE, B.S.; GODWIN, R.J. \& FOUNTAS, S. The analysis of spatial and temporal trends in yield map data over six years. Biosyst. Eng., 84:455-466, 2003.

BONGIOVANNI, R. \& LOWENBERG-DEBOER, J. Precision agriculture and sustainability. Precision Agric., 5:359-387, 2004 .

CAMBARDELLA, C.A.; MOORMAN, T.B.; NOVAK, J.M.; PARKIN, T.B.; KARLEN, D.L.; TURCO, R.F. \& KONOPKA, A.E. Field-scale variability of soil properties in central Iowa soils. Soil Sci. Soc. Am. J., 58:1501-1511, 1994.

CAMBARDELLA, C.A. \& KARLEN, D.L. Spatial analysis of soil fertility parameters. Precision Agric., 1:5-14, 1999.

CARVALHO, J.R.P.; SILVEIRA, P.M. \& VIEIRA, S.R. Geoestatística na determinação da variabilidade espacial de características químicas do solo sob diferentes preparos. Pesq. Agropec. Bras., 37:1151-1159, 2002.

COMISSÃO DE QUÍMICA E FERTILIDADE DO SOLO CQFSRS/SC. Manual de adubação e calagem para os Estados do Rio Grande do Sul e Santa Catarina. Porto Alegre, Sociedade Brasileira de Ciência do Solo - Núcleo Regional Sul, 2004. 400p.

CONCEIĈÃO, P.C.; AMADO, T.J.C.; MIELNICZUK, J. \& SPAGNOLLO, E. Qualidade do solo em sistemas de manejo avaliada pela dinâmica da matéria orgânica e atributos relacionados. R. Bras. Ci. Solo, 29:777-788, 2005. 
CORÁ, J.E.; ARAUJO, A.V.; PEREIRA, G.T. \& BERALDO, J.M.G. Variabilidade espacial de atributos do solo para adoção do sistema de agricultura de precisão na cultura de cana-de-açúcar. R. Bras. Ci. Solo, 28:1013-1021, 2004.

CUNHA, J.P.A.R.; VIEIRA, L.B. \& MAGALHÃES, A.C Resistência mecânica do solo à penetração sob diferentes densidades e teores de água. Eng. Agric., 10:1-4, 2002.

DELIN, S. \& BERGLUND, K. Management zones classified with respect to drought and waterlogging. Precision Agric., 6:321-340, 2005.

EMPRESA BRASILEIRA DE PESQUISA AGROPECUÁRIA EMBRAPA. Centro Nacional de Pesquisa de Solos. Manual de métodos de análise de solo. 2.ed. Rio de Janeiro, Embrapa Solos, 1997. 212p.

EMPRESA BRASILEIRA DE PESQUISA AGROPECUÁRIA EMBRAPA. Centro Nacional de Pesquisa de Solos. Sistema brasileiro de classificação de solos. Rio de Janeiro, 2006. 306p.

FARACO, M.A.; URIBE-OPAZO, M.A.; DA SILVA, E.A.A.; JOHANN, J.A. \& BORSSOI, J.A. Seleção de modelos de variabilidade espacial para elaboração de mapas temáticos de atributos físicos do solo e produtividade da soja. R. Bras. Ci. Solo, 32:463-476, 2008.

GAMMA DESIGN SOFTWARE. Geoestatistics for the environmental sciences. Plainwell, 2000.

GEYPENS, M.; VANONGEVAL, L.; VOGELS, N. \& MEYKENS, J. Spatial variability of agricultural soil fertility parameters in a Gleyic Podzol of Belgium. Precision Agric., 1:319-326, 1999.

GIOTTO, L.; ROBAINA, A.D. \& SULZBACH, L. A agricultura de precisão como o Sistema CR Campeiro5. Santa Maria, Universidade Federal de Santa Maria, 2004. 330p.

GUEDES, L.P.C.; URIBE-OPAZO, M.A.; JOHANN, J.A. \& DE SOUZA, E.G. Anisotropia no estudo da variabilidade espacial de algumas variáveis químicas do solo. R. Bras. Ci. Solo, 32:2217-2226, 2008.

HILLEL, D. Introduction to soil physics. San Diego, Academic Press, 1982. 264p.

ISAAKS, E.H. \& SRIVASTAVA, R.M. An introduction to applied geoestatistics. Oxford, Oxford University Press, 1989. $561 \mathrm{p}$.

KLUTHCOUSKI, J.; FANCELLI, A.L.; DOURADO-NETO, D.; RIBEIRO, C.M. \& FERRARO, L.A. Manejo do solo e o rendimento de soja, milho, feijão e arroz em plantio direto. Sci. Agric., 57:97-104, 2000.

LAMB, J.A.; DOWDY, R.H.; ANDERSON, J.L. \& REHM, G.W Spatial and temporal stability of corn grain yields. J. Prod. Agric., 10:410-414, 1997.

LEMAINSKI, C.L. Agricultura de precisão em áreas irrigadas com pivô central no Rio Grande do Sul. Santa Maria, Universidade Federal de Santa Maria, 2007. 117p. (Tese de Mestrado)

LETEY, J. Relationship between soil physical properties and crop productions. Adv. Soil Sci., 1:277-294, 1985.
LIMA, C.L.R.; SILVA, A.P.; IMHOFF, S. \& LEÃO, T.P. Estimativa da capacidade de suporte de carga do solo a partir da avaliação da resistência a penetração. R. Bras. Ci. Solo, 30:217-223, 2006.

MENEGATTI, L.A.A. Metodologia para identificação, caracterização e remoção de erros em mapas de produtividade. Piracicaba, Escola Superior de Agricultura "Luiz de Queiroz", Universidade de São Paulo. 2002. 84p. (Tese de Mestrado)

MIAO, Y.; MULLA, D.J. \& ROBERT, P.C. Spatial variability of soil properties, corn quality and yield in two Illinois, USA fields: Implications for precision corn management. Precision Agric., 7:5-20, 2006.

MICHELON, C.J.; CARLESSO, R.; PETRY, M.T.; DAVID, G. \& SANTA, C.D. Qualidade física de solos irrigados do Estado do Rio Grande do Sul. Ci Rural, 37:1308-1315, 2007.

MOLIN, J.P. Definição de unidades de manejo a partir de mapas de produtividade. Eng. Agríc., 22:83-92, 2002.

MORENO, J.A. Clima do Rio Grande do Sul. Porto Alegre, Secretaria da Agricultura do Estado do Rio Grande do Sul, Diretoria de Terras e Colonização, Secção de Geografia, 1961. 42p.

NELSON, D.W. \& SOMMERS, L.E. Total carbon, organic carbon and organic matter. In: PAGE, A.L.; MILLER, R.H. \& KENNEY, D.R., eds. Methods of soil analysis: Chemical and microbiological properties. Madison, American Society of Agronomy, 1986. Part 2. p.539-579.

NICOLOSO, R.S.; AMADO, T.J.C.; SCHNEIDER, S.; LANZANOVA, M.E.; GIRARDELLO, V.; BRAGAGNOLO, J. \& GIRARDELLO, R. Eficiência da escarificação mecânica e biológica na melhoria dos atributos físicos de um Latossolo muito argiloso e no incremento do rendimento de soja. R. Bras. Ci. Solo, 32:1723-1734, 2008.

OLIVEIRA, L.B. Determinação da macro e microporosidade pela mesa de tensão em amostras de solo com estrutura indeformada. Pesq. Agropec. Bras., 39:197-200, 1968.

PONTELLI, C.B. Caracterização da variabilidade espacial das características químicas do solo e da produtividade das culturas utilizando as ferramentas da agricultura de precisão. Santa Maria, Universidade Federal de Santa Maria, 2006. 112p. (Tese de Mestrado)

ROZA, D. Novidade no campo: Geotecnologias renovam a agricultura. R. InfoGEO, 11: 2000. Disponível em: <http:/ /www.infogeo.com.br/Revista/materia_11.htm > acesso em: 21 maio 2006

SALVIANO, A.A.C.; VIEIRA, S.R. \& SPAROVEK, G. Variabilidade espacial de atributos de solo e de Crotalaria juncea L. em áreas severamente erodidas. R. Bras. Ci. Solo, 22:115-122, 1998.

SANTI, A.L. Relações entre indicadores de qualidade do solo e a produtividade das culturas em áreas com agricultura de precisão. Santa Maria, Universidade Federal de Santa Maria, 2007. 175p. (Tese de Doutorado)

SECCO, D.; REINERT, D.J.; REICHERT, J.M. \& DA ROS, C.O. Produtividade de soja e propriedades físicas de um Latossolo submetido a sistemas de manejo e compactação do solo. R. Bras. Ci. Solo, 28:797-804, 2004. 
SCHLINDWEIN, J.A. \& ANGHINONI, I. Variabilidade espacial de atributos de fertilidade e amostragem de solo no sistema plantio direto. R. Bras. Ci. Solo, 24:85-91, 2000.

SILVA, V.R.; REINERT, D.J. \& REICHERT, J.M. Resistência mecânica do solo à penetração influenciada pelo tráfego de uma colhedora em dois sistemas de manejo do solo. Ci. Rural, 30:795-801, 2000.

SILVA, V.R.; REICHERT, J.M.; STORCK, L. \& FEIJÓ, S. Variabilidade espacial das características químicas do solo e produtividade de milho em um Argissolo VermelhoAmarelo distrófico arênico. R. Bras. Ci. Solo, 27:1013$1020,2003$.

SILVA, V.R.; REICHERT, J.M. \& REINERT, D.J. Variabilidade espacial da resistência à penetração em plantio direto. $\mathrm{Ci}$. Rural, 34:399-406, 2004.

SUZUKI, L.E.A.; REINERT, D.J.; REICHERT, J.M. \& LIMA, C.L.R. Densidade restritiva ao sistema radicular em função da argila. In: REUNIÃO BRASILEIRA DE MANEJO E CONSERVAÇÃO DO SOLO E DA ÁGUA, 16., Aracajú, 2006. Anais. Recife, 2006. CD ROM.
TAYLOR, H.M.; ROBERTSON, G.M. \& PARKER, J.J. Soil strength root penetration relations for medium to coarse textured soil materials. Soil Sci., 102:18-22, 1966.

TEDESCO, M.J.; GIANELLO, C.; BISSANI, C.A.; BOHNEN, H. \& VOLKWEISS, S.J. Análise de solo, plantas e outros materiais. 2.ed. Porto Alegre, Universidade Federal do Rio Grande do Sul, 1995. 174p. (Boletim Técnico de Solos, 5)

TIMLIN, D.; PACHEPSKY, Y.; WALTHALL, C. \& LOECHEL, $\mathrm{S}$. The use of a water budget model and yield maps to characterize water availability in a landscape. Soil Till. Res., 58:219-231, 2001.

TORMENA, C.A.; BARBOSA, M.C.; COSTA, A.C.S. \& GONÇALVES, A.C.A. Densidade, porosidade e resistência à penetração em Latossolo cultivado sob diferentes sistemas de preparo de solo. Sci. Agríc., 59:795-801, 2002.

WARRICK, A.W. \& NIELSEN, D.R. Spatial variability of soil physical properties in the field. In: HILLEL, D., ed. Applications of soil physics. New York, Academic Press, 1980. p.319-344. 
